\title{
Correlation between shear and normal strength for brittle reinforced concrete member considering internal stress condition of concrete
}

\author{
Walid Ahmad Safi ${ }^{1, *}$ and Yo Hibino ${ }^{1}$ \\ ${ }^{1}$ Graduate School of Engineering, Hiroshima University, Hiroshima, Japan
}

\begin{abstract}
Formulas used to predict shear strength of reinforced concrete in different standards do not always correspond to each other due to the complexity of the shear transfer mechanism. Currently there is no generally accepted method of shear strength pridiction, however, traditionally, shear strength anticipation of a structural concrete elements is performed differently on members with or without shear reinforcement. These empirical approches tend to predict the shear strength too conservatively; alternatively, shear strength of concrete can be easily predicted by MohrCoulomb theory. In case of high-axial load and low shear reinforcement, the strength is likely to be determined by the concrete's shear crack. Therefore, a method to predict the strength of concrete with Mohr-circle has been proposed but the circles crossed the boundary and could not evaluate the strength correctly. Mohr circle can be used for prediction of diagonal tension failure strength but the circle cannot be evaluated. In this paper, Mohr circles were investigated considering all steps of cyclic loading until shear crack occurred. It also investigates a correlation between shear strength and normal strength through recognition of the Mohr-Coulomb failure criteria for each specimen.
\end{abstract}

\section{Introduction}

Formulas used to predict shear strength of reinforced concrete in different standards do not always correspond to each other's prediction due to the complexity of the shear transfer mechanism. The shear strength anticipation of reinforced concrete members has been one of the factfinding topic and therefore numerous researches have been launched (Nielsen et al. [1]; Vecchio and Collins [2, 3]; Bentz, Vecchio and Collins [4]). Currently there is no generally accepted method of shear strength prediction; however, traditionally, shear strength anticipation and checking of structural concrete elements is performed differently on members according to the shear reinforcement. Several well-established theories based on equilibrium considerations can be applied when shear reinforcement is provided, leading to safe design solutions. On the other hand, the actual shear failure mechanism cannot be demonstrated by these approaches and the shear strength is often estimated too conservatively.

As a solution for that issue, Muttoni [5] and Zhang [6] have investigated the shear strength of reinforced concrete members without stirrups based on a critical shear crack. It is realized that recently developed methods are restricted to the certain condition and property of material and cannot be directly applied to new technology.
Therefore, a method is desired for the prediction of shear strength to have applicability over all conditions based on rational shear failure mechanism.

In this paper it is attempted to address correlation between shear and normal strength based on recent improvements of shear strength prediction by MohrCoulomb theory to investigate the shear failure mechanism of reinforced concrete members.

\section{Shear strength prediction with mohr- coulomb criterion}

A shear strength prediction of reinforced concrete members with Mohr-Coulomb criterion has been proposed by Pujol [7]. When the Mohr circle's stress reaches the criterion internally, shear stress is given (See Fig. 1). The Mohr-Coulomb theory is a mathematical model (Fig. 1) describing the response of brittle materials such as concrete, or rubble piles, to shear stress as well as normal stress. The Mohr-Coulomb theory suggests a correlation between normal and shear stress as well as failure load and angle of friction. Coulomb's friction hypothesis is utilized to determine the combination of shear and normal stress that will cause a fracture of concrete. Mohr's circle is used to clarify which principal stresses will produce this combination of shear and

\footnotetext{
* Corresponding author: $\underline{\text { d174422@,hiroshima-u.ac.jp }}$
} 
normal stress, and the angle of the plane in which this will occur. The Mohr-Coulomb failure criterion represents the linear envelope that is obtained from a plot of the shear strength of concrete $\tau$ versus the applied normal stress $\sigma$. This relation is expressed as:

$$
\tau=k_{1} f_{c}^{\prime}+k_{2} \sigma
$$

where $k_{1}$ and $k_{2}$ are the coefficient pertaining to cohesion and internal friction angle of concrete.

Pujol [7] has suggested the following Mohr-Coulomb criteria as the failure envelope;

$$
\tau=0.17 f_{c}^{\prime}+0.75 \sigma
$$

$$
\sigma \leq f_{t}
$$

where $f_{t}$ is the tensile stress of concrete.

The ultimate shear strength given by Mohr-Coulomb criterion has a valid theoretical bases, but the proposed theory is not proven with actual concrete stress and the stress condition inside of a member subjected to axial and horizontal loads. Furthermore, Pujol [7] suggests that the proposed procedure may be too conservative for a column with axial load ratios which are larger than 0.4 and with small amounts of transverse reinforcements. Those conditions are not considered generally for ductile members; however, when it happens the members may show unexpected failure. Therefore, it is important to consider the mechanism of the failure of the members.

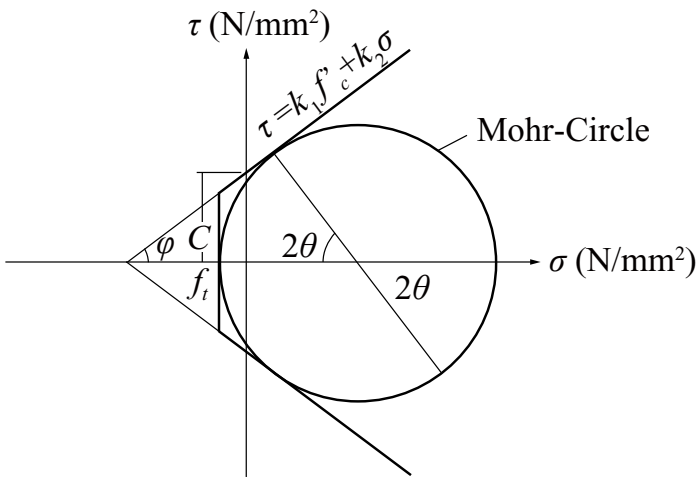

Fig. 1. Mohr-Coulomb criterion

Hibino [8] has tried to propose a method to predict the strength with Mohr-circle of concrete but the circles exceed tensile limit before reaching to maximum stress and therefore the strength could not be evaluated correctly. He also declared that Mohr circle can be used for prediction of diagonal tension failure strength but the circle cannot be evaluated.

In this paper, it is attempted to investigate those Mohrcircles, restricted in the specified boundary of tensile stress and forming failure criteria which based on that correlation between shear and normal strength of the element is modified. To this end, Mohr circles were investigated considering all steps of cyclic loading until fracture, particularly on the step shear crack occurred. Mohr circles which based on that Mohr-coulomb failure criteria for each series of specimen is modified, are investigated for different strain gages, installed inside series of specimen.

Concrete strength in the concrete core section at ultimate state was evaluated. Predicted Mohr stress circles drawn by measured strain depends on the axial load ratio and concrete strength. The combination of large number of circles, evolved from corresponding steps pertaining to the modified strain gage of each specimen, could lead us to find out circles which could reveal the real status inside the concrete as well as fracture limit. Furthermore, the combination of the circles simulates graphical correlation between shear and normal strength and Mohr-Coulomb failure criteria which relatively restate coefficients for Eq. 2 according to experimental records.

\section{Specimen test}

Nine series of specimens, R1; R2 and R3, were designed to investigate internal strength status and failure criteria of brittle reinforced concrete column that has small amounts of transverse reinforcements. Geometric properties were the same in all specimens: the cross section is $120 \mathrm{~mm} \times 200 \mathrm{~mm}$; shear span length is $600 \mathrm{~mm}$; and shear span-to-depth ratio is 1.5. Concrete strength and magnitude of axial load were selected as the parameters, which are shown in Table 1. The configuration of the specimen is shown in Fig. 2. The high strength steel bars, $\mathrm{K} 13$ were used as longitudinal reinforcement and concrete strength $f_{c}^{\prime}, 60 \mathrm{MPa}$ and $80 \mathrm{MPa}$ were used (properties are shown in Table 2 and 3). The transverse reinforcement ratio was arranged so that the column demonstrates brittle

\begin{tabular}{|c|c|c|c|c|c|c|c|c|c|}
\hline Series & Specimen & $\begin{array}{c}b \\
(\mathrm{~mm})\end{array}$ & $\begin{array}{c}d \\
(\mathrm{~mm})\end{array}$ & $\begin{array}{c}L \\
(\mathrm{~mm})\end{array}$ & $M / V d$ & $\begin{array}{c}f_{c}^{\prime} \\
(\mathrm{MPa})\end{array}$ & $\begin{array}{c}\text { Longitudinal } \\
\text { reinforcement }\end{array}$ & $\begin{array}{c}\text { Shear } \\
\text { reinforcement }\end{array}$ & $N_{u} / b d f_{c}^{\prime}$ \\
\hline \multirow{3}{*}{$\mathrm{R} 1$} & $\mathrm{R} 1-0$ & \multirow{9}{*}{120} & \multirow{9}{*}{200} & \multirow{9}{*}{600} & \multirow{9}{*}{1.5} & \multirow{6}{*}{80} & \multirow{9}{*}{$\begin{array}{c}4-\mathrm{K} 13 \\
\left(\rho_{t}=1.17 \%\right)\end{array}$} & \multirow{3}{*}{ D6@260(SD295A) } & 0 \\
\hline & R1-2 & & & & & & & & 0.2 \\
\hline & R1-3 & & & & & & & & 0.3 \\
\hline \multirow{3}{*}{$\mathrm{R} 2$} & R2-0 & & & & & & & \multirow{4}{*}{$\begin{array}{l}\text { D4@100 } \\
\text { (SD295A) }\end{array}$} & 0 \\
\hline & R2-2 & & & & & & & & 0.2 \\
\hline & R2-3 & & & & & & & & 0.3 \\
\hline \multirow{3}{*}{ R3 } & $\mathrm{R} 3-0$ & & & & & \multirow{3}{*}{60} & & & 0 \\
\hline & R3-2 & & & & & & & \multirow{2}{*}{$\begin{array}{l}\text { D6. D4@50 } \\
\text { (SD295A) }\end{array}$} & 0.2 \\
\hline & R3-3 & & & & & & & & 0.3 \\
\hline
\end{tabular}
shear failure. Bi-directional double-curvature cyclic

Table 1. Specimen properties

where $b, d, L$ are width, depth and length of the column respectively. $M / V d$ shows shear span to depth ratio. 
loadings were applied to the specimen under constant axial load $N_{u}$ that simulates gravity load with specified magnitude: $N_{u} / b h f^{\prime} c=0 ; 0.2$; and 0.3 . The loading program was controlled by drift angle $R$, which is given by the relative lateral displacement of column divided by its height $L$. The target drift ratio was $\pm 0.125 \% \times 2$, $\pm 0.25 \% \times 2, \pm 0.5 \% \times 2, \pm 1 \% \times 2, \pm 1.5 \% \times 2$, and $\pm 2 \% \times 2$.

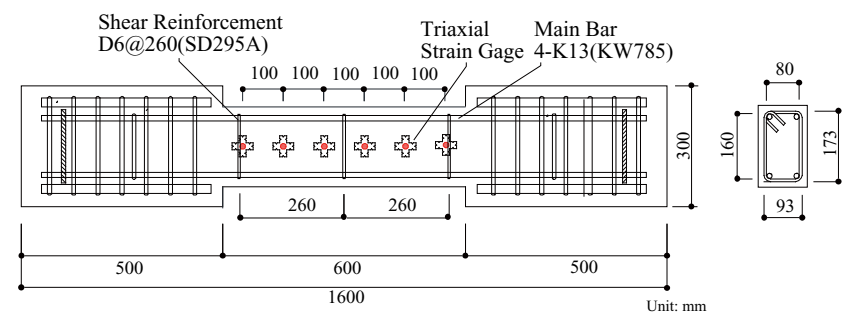

Fig 2. Configuration of specimens

Table 2. Steel properties

\begin{tabular}{|c|c|c|c|c|}
\hline & Strength & $\begin{array}{c}\text { Yield } \\
\text { strength } \\
(\mathrm{MPa})\end{array}$ & $\begin{array}{c}\text { Yield } \\
\text { strain }(\mu)\end{array}$ & $\begin{array}{c}\text { Tensile } \\
\text { strength } f_{t} \\
(\mathrm{MPa})\end{array}$ \\
\hline K13 & KW785 & 859 & 6339 & 1042 \\
\hline D6 & SD295A & 370 & 3370 & 549 \\
\hline D4 & SD295A & 376 & 3389 & 529 \\
\hline
\end{tabular}

Table 3. Concrete properties

\begin{tabular}{|c|c|c|c|}
\hline Series & $\begin{array}{c}\text { Compressive } \\
\text { strength, } f^{\prime} c \\
(\mathrm{MPa})\end{array}$ & $\begin{array}{c}\text { Tensile } \\
\text { strength, } f_{t} \\
(\mathrm{MPa})\end{array}$ & $\begin{array}{c}\text { Modulus of } \\
\text { elasticity } \\
(\mathrm{GPa})\end{array}$ \\
\hline R1 & 82.7 & 5.47 & 44.9 \\
\hline R2 & 76.03 & 5.33 & 43.6 \\
\hline R3 & 72.71 & 5.49 & 45 \\
\hline
\end{tabular}

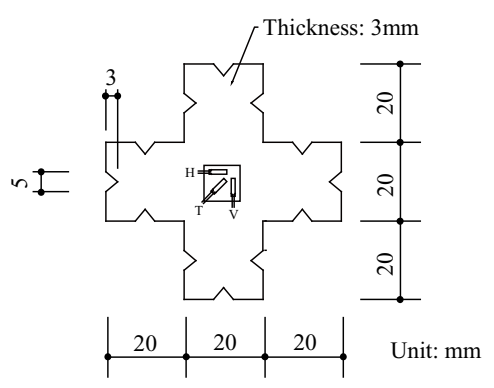

Fig 3. Shape of Triaxle Strain Gage

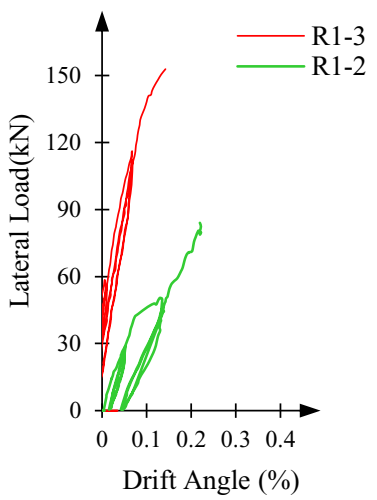

(a) R1 series

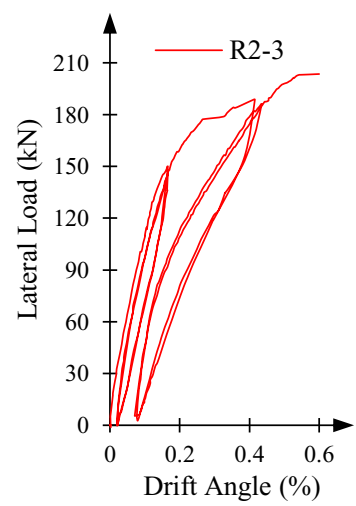

(b) R2 series
To measure the strain and relative strength condition of concrete, acrylic bars furnished with triaxial strain gages were placed in the core section of columns, as shown in Fig. 3. The acrylic bars have serrated configuration to improve bonding performance with concrete. The positon of the triaxial strain gages (SG-1 to SG-6) are shown in Fig. 2.

\section{Experimental Results}

\subsection{Load-deflection response}

The load deflection response of the specimens is shown in Fig. 4. The maximum lateral load increases with the increase of axial load ratio and concrete strength. The lateral load after the maximum point drastically decreased due to the shear failure for all the specimens and all the specimens demonstrated brittle failure. The maximum lateral load $V_{\max }$ and drift angle at the failure, $R_{\max }$ are shown in Table 4 with computed strength given by followings [9].

$$
\begin{gathered}
V_{n}=V_{s t}+V_{c} \\
V_{s t}=\frac{A_{v} f_{y} s}{d} \\
V_{c}=\frac{1}{6}\left(1+0.07 \frac{N_{u}}{A_{g}}\right) \sqrt{f_{c}^{\prime}} b d
\end{gathered}
$$

where, $V_{n}$ is the nominal shear strength, $V_{s t}$ is the shear strength of transverse reinforcement, $V_{c}$ is the shear strength of concrete which can be determined by different formula, generally in case of non-prestressed concrete with axial compression Eq. 6 is used. However, where shear is a substantial governing concern in wellreinforced short, stubby member or well-reinforced members with heavy concentrated loads are exceptional. $A_{v}$ is the shear reinforcement (two bar areas for U-stirrup); $s$ is the spacing between stirrups in a direction parallel to the axis of the member; $N_{u}$ is a compressive axial load in $\mathrm{MPa} ; f_{y}$ and $f_{c}{ }_{c}$ are tensile and compressive strength of steel and concrete respectively.

The observed crack patterns are shown in Fig. 5. Diagonal wide cracks were observed and similar cracks

Fig. 4. Lateral load-drift relationship 
occurred in all the specimens. This procedure is based on the assumption that if shear crack strength $V_{c r}$ is larger than ultimate shear strength $V_{u}$, the shear crack strength governs the maximum strength. The shear crack strength $V_{c r}$ derived from the theoretical model are given by Eq. 7, as shown in Table 4.

$$
V_{c r}=\frac{b d}{1.5} \sqrt{f_{t}^{2}+\frac{f_{t} N_{u}}{b d}}
$$

For all specimens, diagonal shear crack appeared with drastic shear deterioration, the observed failure type was therefore diagonal tension (DT) failure. DT failure is evaluated because shear crack strength $V_{c r}$ shown in Table 4 are larger than computed shear strength $V_{n}$ shown in Table 4. Fig. 6 shows the comparison of experimental results $V_{\max }, V_{c r}$ and $V_{n}$. The shear crack strength $V_{c r}$ overestimates measured shear strength for all the specimens and the shear strength $V_{u}$ underestimates the shear strength. This disagreement between computed and measured shear strength suggests that DT failure can be determined by neither tension failure of concrete assumed in the shear crack strength $V_{c r}$ nor compression failure of concrete assumed in the nominal shear strength $V_{n}$.

\subsection{Mohr-Coulomb Failure Envelope}

The Mohr-Coulomb criteria is defined as the tangential line to those Mohr circles which have maximum diameter corresponding modified limit. Mohr circles are plotted for each step of cyclic loading corresponding to $\sigma_{\max }$ and $\sigma_{\min }$, created inside the specimen. Based on experimental records for each specimen, step corresponding failure of specimen are considered as a margin of strains and proportional strengths.

Table 4. Strength and failure type of specimen

\begin{tabular}{|c|c|c|c|c|}
\hline \multicolumn{2}{|c|}{ Specimen } & $V_{\max }(\mathrm{kN})$ & $V_{c r}(\mathrm{kN})$ & $V_{n}(\mathrm{kN})$ \\
\hline \multirow{4}{*}{ R1 } & $\mathrm{R} 1-0$ & 71 & 88 & 42 \\
\cline { 2 - 5 } & $\mathrm{R} 1-2$ & 84 & 255 & 76 \\
\cline { 2 - 5 } & $\mathrm{R} 1-3$ & 183 & 320 & 99 \\
\hline \multirow{4}{*}{ R2 } & $\mathrm{R} 2-0$ & 91 & 86 & 43 \\
\cline { 2 - 5 } & $\mathrm{R} 2-2$ & 121 & 255 & 74 \\
\cline { 2 - 5 } & $\mathrm{R} 2-3$ & 204 & 309 & 91 \\
\hline \multirow{4}{*}{ R3 } & $\mathrm{R} 3-0$ & 65 & 88 & 58 \\
\cline { 2 - 5 } & $\mathrm{R} 3-2$ & 164 & 222 & 63 \\
\cline { 2 - 5 } & $\mathrm{R} 3-3$ & 188 & 310 & 88 \\
\hline
\end{tabular}

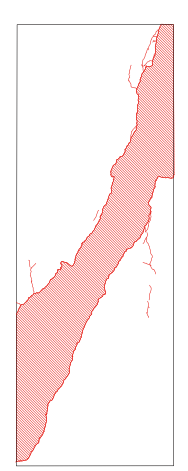

(a) R1-2

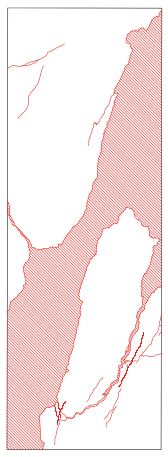

(b) R1-3

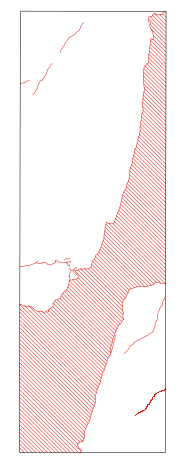

(c) R2-3

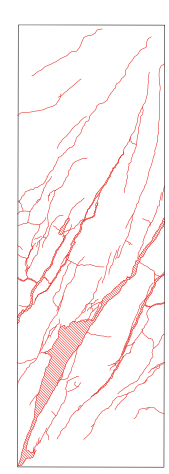

(d) R3-1
Fig. 5. Crack drawings
In order to recognize any ambiguous step which may have been recorded by slipped strain gages prior to reaching the cracking boundary, all data taken from strain gages are checked. Mohr circles are plotted based on concrete strain, resulted inside the specimen from every step of cyclic loading until the shear crack is revealed. Among these circles if there were any circle crossing tension strength of the concrete (Eq. 8) in tensile zone, the step is neglected and considered as a boundary for remaining data.

$$
f_{t}=\frac{1}{12} \sqrt{f_{c}^{\prime}}
$$

Mohr circles are investigated by using Rosette analysies for each step of cyclic loading until cracking.

According to Rosette analysies, the maximum principal stress $\sigma_{\max }$ and minimum stress $\sigma_{\min }$ of core concrete measured by triaxial strain gages are derived by the following equations.

$$
\begin{gathered}
\sigma_{\max }=\frac{E_{c}}{1-v^{2}}\left(\epsilon_{\max }+v \epsilon_{\min }\right) \\
\sigma_{\min }=\frac{E_{c}}{1-v^{2}}\left(\epsilon_{\min }+v \epsilon_{\max }\right)
\end{gathered}
$$

where $\varepsilon_{\max }$ is maximum principal strain; $\varepsilon_{\min }$ is minimum principal strain; $v$ is Poisson's ratio $(=0.2)$.

The principal strains were calculated by measured strains using Rosette analysis. Note that stress-strain characteristic of concrete was idealized by elastic perfectly plastic approximation. Mohr circles are plotted for each steps of cyclic loading of each strain gage separately as shown in Fig. 7; this is to differentiate concrete recorded strain and combined recorded strain which comprised from acrylic bars strain as well as strain gage sliding. Mohr circles derived through this process are combined together to simulate a Mohr-Coulombs failure envelope as shown in Fig. 8. Those series which have experienced short drift until peak loading manifest the critical status of concrete strength.

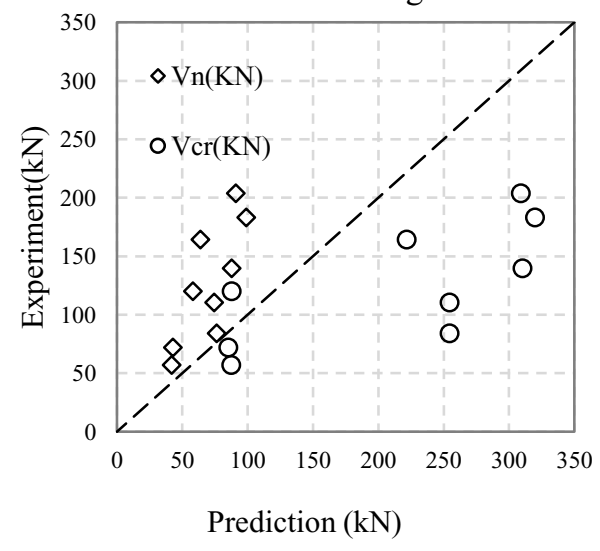

Fig. 6. Comparison $V_{\max }, V_{c r}$ and $V_{u}$

A series of experiments shown in Fig. 8 was realized to test relatively lower drift until maximum cyclic loading in order to verify the status. Blue dashed circles in Fig. 8 illustrate the strength condition of concrete which is 


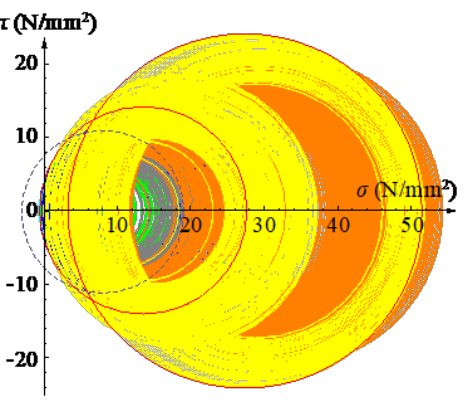

(a) R1-3

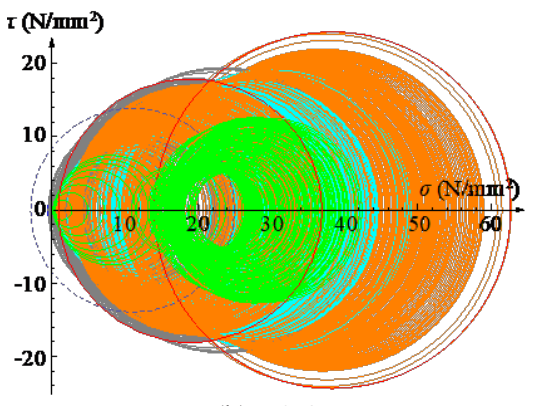

(b) R2-3

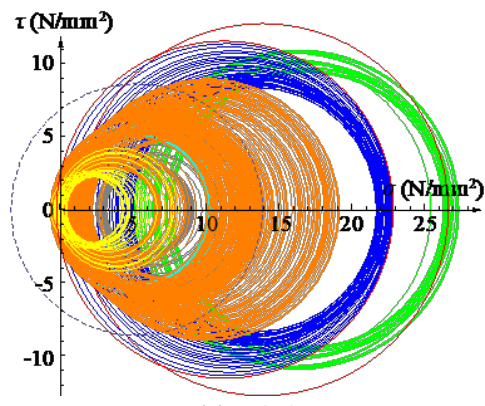

(c) R3-2

Fig. 7. Set of Mohr circles combined from all strain gages of series

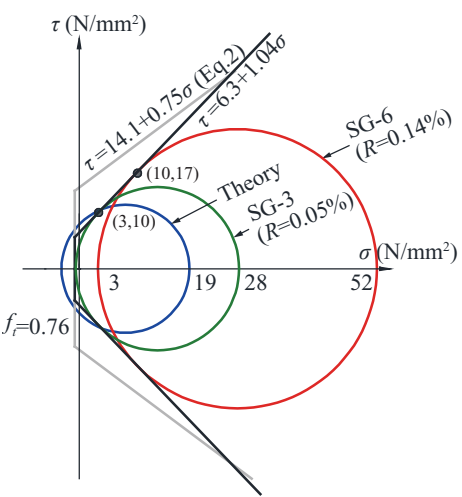

(a) R1-3

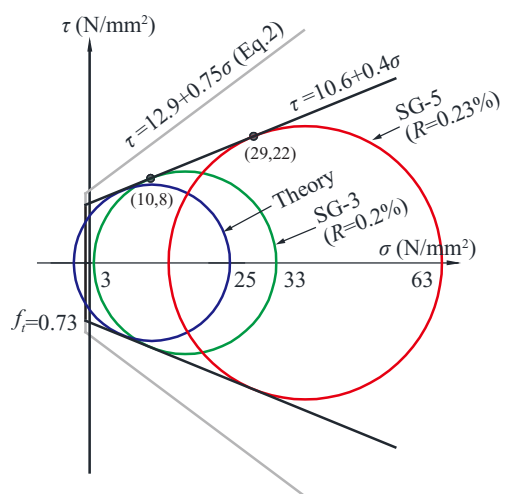

(b) R2-3

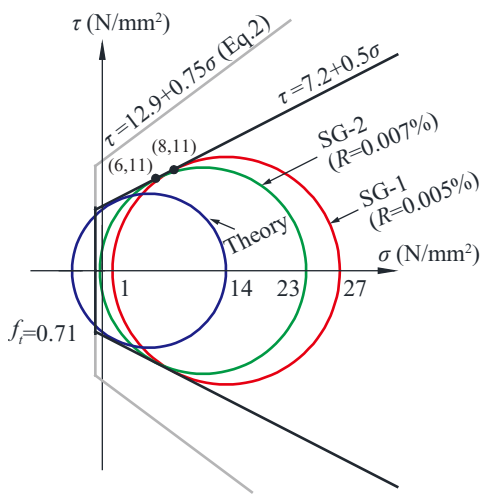

(c) R3-2

Fig. 8. Mohr-Coulomb failure criteria of series

computed based on the theoretical equation of shear $\tau_{x y}$ and normal stress $\sigma_{x}$ of Eq. 11 and Eq. 12 for maximum cyclic loading.

$$
\begin{gathered}
\sigma_{x}=\frac{N_{u}}{b d} \\
\tau_{x y}=\frac{Q}{b d}
\end{gathered}
$$

where $N_{u}$ and $Q$ are maximum applied axial and shear load corresponding failure of specimen.

Mohr stress circles resulting from the theoretical analysis are smaller compared to the largest circle of concrete stress, resulting from experiment data. The largest stress circles (red circles in Fig. 8) show the cracking shear stress of concrete.

The difference between theoretical and experimental based Mohr circles expresses variation of acting shear force through every concrete fiber. This shows that Eq. 11 and Eq. 12 can be used to observe the concrete status in a complimentary status rather than critical condition. Mohr circles which predict largest strength capacity of each series (red circles) are selected for recognition of MohrCoulomb failure envelope in Fig. 8.

The Mohr-coulomb criterion illustrated in Fig. 8 suggests that angle of fracture as well as correlation of shear and normal strength are not constant for all of the specimen but is a function of different parameters such as drift angle, concrete compressive strength, failure type, axial load and shear web reinforcement. Specimen series R1-3 addressed the above mentioned assumption.

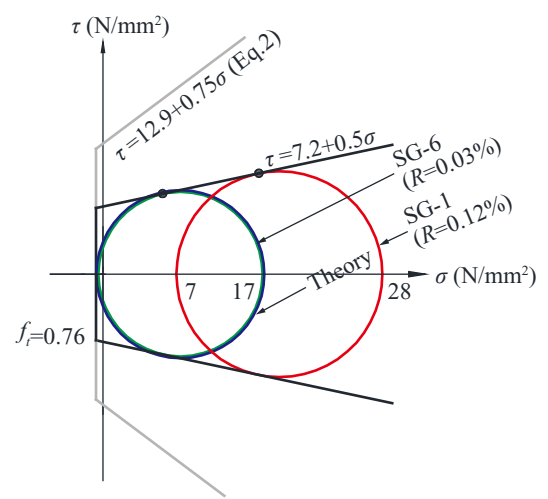

Fig. 9. Mohr-Coulomb failure envelope (R1-2)

On the other hand, Mohr circles resulted from mentioned series either crossed from concrete tensile strength (Eq. 8) in the early steps or simulate retrogress failure envelope Fig. 9. Therefore shear and normal strength fracture criterion for experimental and Eq. 2 is compared, as shown in Fig. 10. Correlation between shear and normal strength is suggested for R1-3, R1-2, R2-3, R3-2 series as shown in Fig. 10 and compared with Eq. 2 Some these of these series equation cross the Eq. 2 criterion at high stress condition. Failure coordinate of each specimen shown in Fig. 10 as well as in Fig. 8.

\section{Conclusion}

1. Mohr stress circle drawn by concrete stress showed different diameter and shape according to the axial 


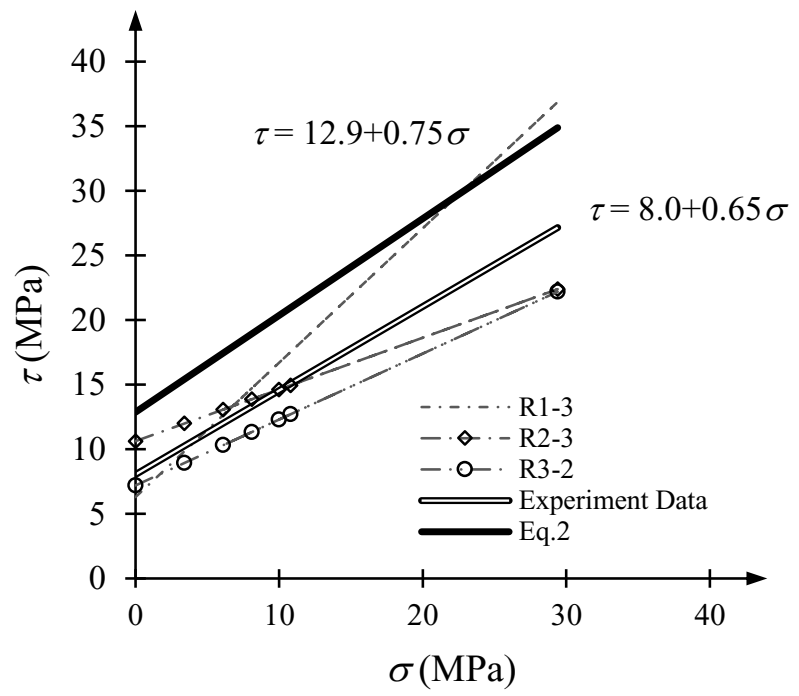

Fig. 10. Comparison of experimental and theoretical equations

load ratio and Diameter of Mohr stress circle of specimen with high axial load ratio became lager than that of the specimen with lower axial load ratio.

2. The Mohr-Coulomb failure envelopes investigated showed that the angle of fracture of concrete as well as correlation of shear and normal strength are not constant for all of the specimens, but is a function of different parameters such as drift angle, concrete compressive strength, failure type, axial load and shear web reinforcement.

3. It is realized that concrete Mohr stress circles resulting from the theoretical analysis can predict shear strength of a member in the complimentary status rather than critical condition inside the member.

4. The series of specimen examined in this study realized that the shear strength prediction formula underestimate the shear strength and Mohr-Coulomb modified criteria overestimate the shear strength.

5. Shear is initially resisted by three shear-carrying mechanisms: cantilever action, aggregate interlock, and dowel action. These mechanisms create a state of tensile stresses in the concrete that leads to the development of the critical shear crack.

\section{References}

1. M. P. Nielsen, M. W. Braestrup, B. C. Jensen, F. Bach, Concrete Plasticity, Beam Shear-Shear in Joints-Punching Shear, Special Publication, Danish Society for Structural Science and Engineering (1978)

2. F. J. Vecchio, M. P. Collins, The Modifie Compression-field Theory for Reinforced-concrete Elements Subjected to Shear, Journal of the AmericanConcrete Institute, 83 (2), 219-231 (1986)

3. F. J. Vecchio, M. P. Collins, Predicting the Response of Reinforced-concrete Beams Subjected to Shear using Modified Compression Field-theory, ACI Structural Journal, 85 (3), 258-268 (1988)
4. E. C. Bentz, F. J. Vecchio, M. R. Collins, Simplified Modified Compression Field Theory for Calculating Shear Strength of Reinforced Concrete Elements, ACI Structural Journal, 103 (4), 614-624 (2006)

5. A. Muttoni, M. F. RuizShear, Strength of Members without Transverse Reinforcement as Function of Critical Shear Crack Width, ACI Structural Journal, 105 (2), 163-172 (2008)

6. T. Zhang, P. Visintin, D. J. Oehlers, Shear strength of RC beams without web Reinforcement, Australian Journal of Structural Engineering, 17 (1), 87-96 (2016)

7. S. Pujol, N. Hanai, T. Ichinose, M. A. Sozen, Using Mohr-Coulomb Criterion to Estimate Shear Strength of Reinforced Concrete Columns, ACI Structural Journal, American Concrete Institute, 113 (3), 459468 (2016)

8. Y. Hibino, Y. Yamaki, Shear Strength Prediction For Brittle Reinforced Concrete Member Considering Concrete Stress Conditions, Proceedings of the 16th World Conference on Earthquake, Paper $\mathrm{N}^{\circ} 2810$ (2017)

9. ACI Committee 318 , Building Code Requirements for Structural Concrete (ACI 318-14) and Commentary (ACI 318R-14), American Concrete Institute, Farmington Hills (2014) 